\title{
Do We Have to Obtain Rebound Bilirubin Levels and What is the Optimal Time?
}

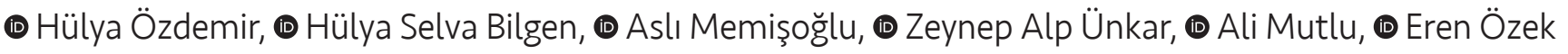 \\ Marmara University Faculty of Medicine, Department of Pediatrics, Division of Neonatology, İstanbul, Turkey
}

\begin{abstract}
Aim: We aimed to determine the frequency of rebound hyperbilirubinemia (RHB) needing treatment and therefrom, to clarify the clinical importance of routinely checking serum total bilirubin (STB) levels after the cessation of phototherapy and to define an optimal time to check STB levels for the detection of RHB.

Materials and Methods: Term and late preterm babies who received phototherapy were included in this study. The demographic and clinical features, time of onset of jaundice, phototherapy time and results to determine the etiology of jaundice were recorded for all babies. Serum "rebound" bilirubin measurements were performed two times at 12 and at 24 hours after the cessation of phototherapy. The re-initiation of phototherapy according to the $12^{\text {th }}$ and $24^{\text {th }}$ hour STB levels was accepted as "early rebound" and "late rebound", respectively. IBM SPSS 22 was used for statistical analyses.

Results: Data was available for 110 infants. The rebound rate requiring phototherapy was $9.1 \%(n=10)$ and all had a risk factor. Most of the babies $(9 / 10)$ rebounded at the $12^{\text {th }}$ hour after the termination of phototherapy. Hemolysis and prematurity were found to be statistically significant for RHB ( $p=0.008 ; p=0.048)$.

Conclusion: Post-phototherapy bilirubin follow-up may be incorporated using a combined approach of individualization, evaluation of risk factors, and application of common sense before discharge. Our study showed that STB levels could be measured after the cessation of phototherapy, especially in patients with a risk factor, at the $12^{\text {th }}$ hour before discharge. Randomized controlled studies with larger sample sizes are still needed for definitive recommendations.
\end{abstract}

Keywords: Hyperbilirubinemia, newborn, phototherapy, rebound bilirubin

\section{Introduction}

Phototherapy is the most effective method to lower serum total bilirubin (STB) levels in newborns with hyperbilirubinemia. A sudden increase in bilirubin levels, depending on the cause of hyperbilirubinemia, may be observed after the cessation of phototherapy $(1,2)$. This situation brings forth a discussion on whether to re-check bilirubin levels after phototherapy has been stopped. As the results of the studies about this dilemma are assessed, there is still no consensus about this subject (2-11). The American Academy of Pediatrics (AAP) recommends to measure bilirubin levels within 24 hours after cessation of phototherapy only in cases caused by hemolysis or in those who needed phototherapy in the first three to four days of life (2).

The incidence of hyperbilirubinemia varies with ethnicity and geography and our country is located in this highrisk area (12). Sarici et al. (13) reported the incidence of hyperbilirubinemia as $10.5 \%$ for term and $25.3 \%$ for near- 
term infants in Turkey, which is much higher than the incidence reported from European countries and the United States $(14,15)$. Thus, guidelines developed from those countries may not apply to our country.

The primary aim of our study is to determine the frequency of rebound hyperbilirubinemia (RHB) needing treatment and therefrom, to clarify the clinical importance of routinely checking STB levels after the cessation phototherapy and to define an optimal time to check STB levels for the detection of RHB.

\section{Materials and Methods}

Term and late-preterm babies, who received phototherapy due to hyperbilirubinemia in the Neonatal Intensive Care Unit of Marmara University Medical Faculty between January 2015 and December 2015, were enrolled in this prospective study. Newborns with congenital anomalies or any disease accompanying hyperbilirubinemia (sepsis, pneumonia, perinatal asphyxia, etc.) were excluded. The study was approved by the Ethics Committee of Marmara University Medical Faculty (approval number: 09.2016.231). Informed consent was obtained from the parents of the infants. Infants with RHB and without RHB were compared in terms of their demographic and clinical characteristics, at the $12^{\text {th }}$ and $24^{\text {th }}$ hour STB levels after inpatient phototherapy, time of onset of jaundice, phototherapy period and in terms of the results of all tests performed to determine etiology (blood type of the mother and the baby, reticulocyte count, direct Coombs test, peripheral smear, glucose- 6 phosphate dehydrogenase enzyme levels, thyroid function tests, reducing substances in urine). Late preterm infants are defined as those born at 34-0/7 to 36-6/7 weeks' gestational age (16). Phototherapy and exchange transfusion decisions were made according to the AAP's guidelines and highdensity light-emitting diode phototherapy was initiated on all patients (2).

The "early treatment group" consisted of the infants who received phototherapy before the $72^{\text {nd }}$ hour of life and the "late treatment group" consisted of the infants who received phototherapy after the $72^{\text {nd }}$ hour of life. Phototherapy was discontinued when STB levels dropped below 13-14 mg/dL in the late treatment group and $3 \mathrm{mg} / \mathrm{dL}$ or more below the phototherapy threshold level according to postnatal age in the early treatment group $(17,18)$. RHB was defined as the return of TSB to the phototherapy threshold within 72 hours of phototherapy. Serum rebound bilirubin levels were measured twice; at the $12^{\text {th }}$ hour and $24^{\text {th }}$ hour after the cessation of phototherapy. The need for the re-initiation of phototherapy at the $12^{\text {th }}$ or $24^{\text {th }}$ hour STB levels were accepted as "early rebound" and "late rebound", respectively.

\section{Statistical Analysis}

The distribution of the data was determined by Kolmogorov-Smirnov test. Independent samples t-test and Mann-Whitney $U$ tests were used to compare normallydistributed (parametric) and not normally-distributed (nonparametric) data, respectively. Results were expressed as "mean \pm standard deviation" for parametric data and "median (minimum-maximum)" for non-parametric data. Fisher's exact test and chi-square test was performed for non-parametric variables between groups where appropriate. IBM SPSS Statistics 22 (SPSS Inc., Chicago, IL, $A B D)$ was used for statistical analyses. For all statistical analysis, $p$ values $<0.05$ were considered significant.

\section{Results}

One hundred and ten infants who were treated due to hyperbilirubinemia were included in the present study. Ninety-one infants (83\%) were term and 19 (17\%) were late-preterm with mean birth weights of $3.273 \pm 462 \mathrm{~g}$ and $2.513 \pm 534$ g; respectively. When the cases were assessed for jaundice etiologies, the number of cases with hemolysis due to $\mathrm{ABO}$ or Rh incompatibility, excessive weight loss (loss of $\geq 10 \%$ of birth weight) and prematurity were 17 (15\%), 20 $(18 \%)$ and 19 (17\%), respectively. No etiological factor could be detected in 59 (53\%) infants (Table I). Six babies received exchange transfusion ( $n=1, R h$ incompatibilities and $n=5$, ABO incompatibilities).

The rebound rate was $9.1 \%$ (10/110). There were no significantly statistically differences between rebound and non-rebound groups in terms of birth weight, gestational weeks, gender, prematurity, delivery route, history of jaundice in sibling or excessive weight loss after birth (Table 2). The presence of hemolysis and early phototherapy were found to be statistically significant between the groups, $(p=0.008, p=0.034)$ respectively (Table $I)$. When the two groups were compared according to the rebound frequency, the number of RHB cases in the early phototherapy group was significantly higher $(8 / 10 ; p<0.001)$. Nine of the 10 infants $(90 \%)$ with RHB were detected at testing of STB levels at the $12^{\text {th }}$ hour. Hemolysis and being late-preterm were found to be statistically significant higher for those babies with RHB ( $p=0.008, p=0.048)$ (Table II). The clinical features of those infants with RHB are shown in Table III.

\section{Discussion}

The necessity of rebound STB measurements in newborn jaundice cases is controversial $(2,5,9,10)$. In our research, the $\mathrm{RHB}$ rate was calculated at $9.1 \%$. In recent studies, the occurrence of RHB was reported to be between 0.7\%-19.6\% $(7,19)$. The wide range of the reported frequencies could be 
Table I. Demographic and clinical features of the study population

\begin{tabular}{|c|c|}
\hline & $\begin{array}{l}\text { Study group } \\
(n=110)\end{array}$ \\
\hline Male, n (\%) & $68(61.81)$ \\
\hline Late preterm, n (\%) & $19(17.27)$ \\
\hline \multicolumn{2}{|l|}{ Birth weight, (g) } \\
\hline Term/late-preterm & $3.273 \pm 462 / 2.513 \pm 534$ \\
\hline Cesarean delivery, n (\%) & $53(48.18)$ \\
\hline Family history of jaundice, $\mathrm{n}(\%)$ & $11(10.00)$ \\
\hline \multicolumn{2}{|l|}{ Etiology, n (\%) } \\
\hline Hemolysis, n (\%) & $17(15.45)$ \\
\hline Late-preterm, n (\%) & $19(17.27)$ \\
\hline Excessive weight loss, n (\%) & $20(18.18)$ \\
\hline No etiological factor, n (\%) & $59(53.63)$ \\
\hline Exchange transfusion, $\mathrm{n}(\%)$ & $6(5.45)$ \\
\hline Early-treated hyperbilirubinemia, n (\%) & $56(50.90)$ \\
\hline Time of initiation of phototherapy (hours) & $97(3-192)$ \\
\hline $\begin{array}{l}\text { Serum total bilirubin level at the beginning } \\
\text { of phototherapy }(\mathrm{mg} / \mathrm{dL})\end{array}$ & $17.63 \pm 5.52$ \\
\hline $\begin{array}{l}\text { STB level at the end of phototherapy (mg/ } \\
\mathrm{dL} \text { ) }\end{array}$ & $11.33 \pm 1.87$ \\
\hline Duration of phototherapy (hours) & $24(8-72)$ \\
\hline $12^{\text {th }}$ hour rebound STB $(\mathrm{mg} / \mathrm{dL})$ & $11.53 \pm 2.42$ \\
\hline $24^{\text {th }}$ hour rebound STB $(\mathrm{mg} / \mathrm{dL})$ & $11.38 \pm 2.30$ \\
\hline
\end{tabular}

Data of variables are expressed as mean \pm standard deviation or median (minimum-maximum) or absolute number and its frequencies $\mathrm{n}(\%)$; STB: Serum total bilirubin

\begin{tabular}{|c|c|c|c|}
\hline & $\begin{array}{l}\text { Rebound } \\
\text { group } \\
(n=10)\end{array}$ & $\begin{array}{l}\text { No-rebound } \\
\text { group } \\
(n=100)\end{array}$ & $\mathrm{p}$ value \\
\hline Birth weight (g) & $3045 \pm 536$ & $3201 \pm 508$ & 0.358 \\
\hline Gestational weeks & $37.61 \pm 2.01$ & $38.32 \pm 1.43$ & 0.144 \\
\hline Male, n (\%) & $5(50.00)$ & $63(63.00)$ & 0.501 \\
\hline Term, n (\%) & $6(60.00)$ & $85(85.00)$ & - \\
\hline Late-preterm, n (\%) & $4(40.00)$ & $15(15.00)$ & 0.048 \\
\hline Vaginal delivery, n (\%) & $5(50.00)$ & $52(52.00)$ & 1.000 \\
\hline Hemolysis, n (\%) & $5(50.00)$ & $12(12.00)$ & 0.008 \\
\hline $\begin{array}{l}\text { Weight loss of } \geq 10 \% \text { of } \\
\text { birth weight, } n(\%)\end{array}$ & $3(30.00)$ & $17(17.00)$ & 0.385 \\
\hline $\begin{array}{l}\text { No etiological factor, } \\
\mathrm{n}(\%)\end{array}$ & $0(0)$ & $59(59)$ & $<0.001$ \\
\hline $\begin{array}{l}\text { Early phototherapy, } \mathrm{n} \\
(\%)\end{array}$ & $8(80.00)$ & $48(48.00)$ & 0.034 \\
\hline $\begin{array}{l}\text { STB level at the } \\
\text { beginning of } \\
\text { phototherapy }(\mathrm{mg} / \mathrm{dL})\end{array}$ & $19.48 \pm 7.29$ & $17.70 \pm 5.11$ & 0.315 \\
\hline $\begin{array}{l}\text { STB level at the end of } \\
\text { phototherapy }(\mathrm{mg} / \mathrm{dL})\end{array}$ & $11.24 \pm 2.13$ & $11.10 \pm 2.01$ & 0.822 \\
\hline $\begin{array}{l}12^{\text {th }} \text { - hour rebound, } n \\
(\%)\end{array}$ & $9(90)$ & 0 & $<0.001$ \\
\hline $\begin{array}{l}24^{\text {th }} \text { - hour rebound, } n \\
(\%)\end{array}$ & $1(10)$ & 0 & 0.001 \\
\hline
\end{tabular}

Data of variables are expressed as mean \pm standard deviation (range) or median (minimum-maximum) or absolute number and its frequencies $\mathrm{n}(\%)$ STB: Serum total bilirubin

Table III. Clinical features of the patients with rebound hyperbilirubinemia

\begin{tabular}{|c|c|c|c|c|c|c|c|}
\hline & $\begin{array}{l}\text { Early treatment } \\
\text { group }\end{array}$ & $\begin{array}{l}\text { Late treatment } \\
\text { group }\end{array}$ & $12^{\text {th }}$ rebound & $24^{\text {th }}$ rebound & Hemolysis & $\begin{array}{l}\text { Excessive } \\
\text { weight loss }\end{array}$ & $\begin{array}{l}\text { Late } \\
\text { preterm } \\
\text { infant }\end{array}$ \\
\hline Case 1 & + & - & + & - & - & + & + \\
\hline Case 2 & + & - & + & - & - & + & + \\
\hline Case 3 & - & + & + & - & - & + & - \\
\hline Case 4 & + & - & + & - & + & - & - \\
\hline Case 5 & + & - & + & - & - & - & + \\
\hline Case 6 & + & - & + & - & + & - & - \\
\hline Case 7 & - & + & - & + & - & - & + \\
\hline Case 8 & + & - & + & - & + & - & - \\
\hline Case 9 & + & - & + & - & + & - & - \\
\hline Case 10 & + & - & + & - & + & - & - \\
\hline
\end{tabular}


explained by the differences in the definitions of RHB, sample sizes, jaundice etiologies and risk factors (3-5,8-10,19). Chang at al. (18) reported a $4.6 \%$ rate of RHB; whereas, Barak et al. (19) found a higher rate (19.6\%) and this increased rate was attributed to the discontinuation of phototherapy in cases with higher STB levels (18). In another study, the rebound frequency was recorded as $0.7 \%$ and the exclusion of risk groups was held accountable for this low prevalence (7). The RHB rate has been reported as $5.1 \%$ in Turkey, which is lower than our study (5). The lower mean bilirubin levels at which to start and stop phototherapy and the lower number of cases with blood group incompatibility and hemolysis, compared to our study group, might explain the difference.

Waiting for a rebound STB level measurement prolongs hospital stay; therefore, AAP recommends rebound measurements only in babies with certain risk factors (2). In one study, gestational and postnatal age, and STB levels at the time of cessation of phototherapy were reported as the three most important risk factors for RHB (18). It has been reported in many studies that late-preterm infants, who have the highest risk for newborn jaundice, also have a high "rebound" rate $(5,10)$. In our study, RHB developed in 4 of the 19 late-preterm babies (21\%), which was higher compared to term babies (6\%). Two of these "rebounding" late preterm babies were in the early treatment group, both having excessive weight loss. Kaplan et al. (9) reported that the majority of their rebound cases were late-preterm infants and all had hemolysis.

Those infants who received phototherapy before their initial discharge after birth (in the first three days of life) were reported to have a higher rate of being hospitalized for a second course of phototherapy $(7,9)$. In our study, 9 of the infants with RHB (90\%) were in the early treatment group. Kaplan et al. (9) stated that neonates with hemolysis, late prematurity and onset of phototherapy within 72 hours should be regarded as high risk. In our study, all of the cases with RHB had at least one of these risk factors (hemolysis, excessive weight loss or prematurity).

In the literature, the measurements of rebound STB levels were performed between 8 to 36 hours after the cessation of phototherapy $(3,5,7,9,10)$. AAP recommends the measurement of rebound STB levels within 24 hours of phototherapy cessation, without specifying an exact period (2). "The National Institute for Health and Clinical Excellence", and the "Canadian Paediatric Society Fetus and Newborn Committee" do not refer to the evaluation of rebound STB levels in their guidelines $(17,20)$. In our study, rebound STB levels were measured in two-time sections $\left(12^{\text {th }}\right.$ hour and $24^{\text {th }}$ hour) and it was detected that most of the "rebounds" had developed by the $12^{\text {th }}$ hour measurement and all of them had risk factors. Nine of 10 infants with RHB were detected with the measurement of $12^{\text {th }}$ hour rebound STB levels, thus enabling an early initiation of treatment. Even though AAP recommends outpatient evaluation for rebound STB level, in our country, as we are concerned about the lack of follow-up, we suggest checking rebound STB levels at the $12^{\text {th }}$ hour, before discharge.

\section{Conclusion}

Post-phototherapy bilirubin follow-up may be incorporated using a combined approach of individualization, evaluation of risk factors, and application of common sense before discharge. Our study showed that STB levels can be measured after the cessation of phototherapy, especially in patients with a risk factor, at the $12^{\text {th }}$ hour before discharge. Randomized controlled studies with larger sample sizes are still needed for definitive recommendations.

\section{Ethics}

Ethics Committee Approval: The study was approved by the Ethics Committee of Marmara University Medical Faculty (approval number: 09.2016.231).

Informed Consent: Informed consent was obtained from the parents of the infants.

Peer-review: External and internal peer-reviewed.

\section{Authorship Contributions}

Surgical and Medical Practices: H.Ö., A.M., Z.A.Ü., Concept: H.Ö., H.S.B., Design: H.Ö., H.S.B., Data Collection or Processing: H.Ö., A.M., Z.A.Ü., Analysis or Interpretation: H.Ö., H.S.B., E.Ö., Literature Search: H.Ö., H.S.B., Writing: H.Ö., H.S.B.

Conflict of Interest: The authors have no conflicts of interest to declare.

Financial Disclosure: There are no financial relationships relevant to this article to disclose.

\section{References}

1. Bhutani VK. Committee on Fetus and Newborn; American Academy of Pediatrics. Phototherapy to prevent severe neonatal hyperbilirubinemia in the newborn infant 35 or more weeks of gestation. Pediatrics 2011;128:1046-52.

2. American Academy of Pediatrics Subcommittee on Hyperbilirubinemia. Management of Hyperbilirubinemia in the Newborn Infant 35 or More Weeks of Gestation. Pediatrics 2004;114:297-316.

3. Yetman RJ, Parks DK, Huseby V, Mistry K, Garcia J. Rebound bilirubin levels in infants receiving phototherapy. I Pediatr 1998;133:705-7.

4. Al-Saedi SA. Rebound hyperbilirubinemia in term infants after phototherapy. Saudi Med I 2002;23:1394-7.

5. Erdeve O, Tiras U, DallarY. Rebound bilirubin measurement is not required for hyperbilirubinemia regardless of the background attributes of the newborns. I Trop Pediatr 2004;50:309. 
6. Brown AK, Kim MH, Wu PY, Bryla DA. Efficacy of phototherapy in prevention and management of neonatal hyperbilirubinemia. Pediatrics 1985;75:393-400.

7. Maisels MJ, Kring E. Rebound in serum bilirubin level following intensive phototherapy. Arch Pediatr Adolesc Med 2002;156:669-72.

8. Lazar L, Litwin A, Merlob P. Phototherapy for neonatal nonhemolytic hyperbilirubinemia. Analysis of rebound and indications for discontinuing therapy. Clin Pediatr (Phila) 1993;32:264-7.

9. Kaplan M, Kaplan E, Hammerman C, Algur N, Bromiker R, Schimmel MS, et al. Post-phototherapy neonatal bilirubin rebound: a potential cause of significant hyperbilirubinaemia. Arch Dis Child 2006;91:31-4.

10. Bansal A, Jain S, Parmar VR, Chawla D. Bilirubin rebound after intensive phototherapy for neonatal jaundice. Indian Pediatr 2010;47:607-9.

11. Del Vecchio MT, Benstock MA, Sundel ER. Bilirubin rebound. Pediatr 1999;135:531-2.

12. Linn S, Schoenbaum SC, Monson RR, Rosner B, Stubblefield PG, Ryan KJ. Epidemiology of neonatal hyperbilirubinemia. Pediatrics 1985;75:770-4.

13. Sarici SU, Serdar MA, Korkmaz A, Erdem G, Oran O, Tekinalp G, Yurdakök M, Yigit S. Incidence, course, and prediction of hyperbilirubinemia in near-term and term newborns. Pediatrics 2004;113:775-80
14. Burke BL, Robbins JM, Bird TM, Hobbs CA, Nesmith C, Tilford JM. Trends in hospitalizations for neonatal jaundice and kernicterus in the United States, 1988-2005. Pediatrics 2009;123:524-32.

15. Olusanya BO, Osibanjo FB, Slusher TM. Risk factors for severe neonatal hyperbilirubinemia in low and middle-income countries: a systematic review and meta-analysis. PLoS One 2015;10:e0117229

16. Committee on Obstetric Practice. ACOG Committee Opinion No. 404 April 2008. Late-preterm infants. Obstet Gynecol 2008;111:1029-32.

17. National Institute for Health and Care Excellence. Neonatal jaundice (NICE Clinical Guideline 98). London, England: National Institute for Health and Clinical Excellence; May 2010. Available at: https://www.nice.org.uk/guidance/cg98. Accessed February 23, 2016.

18. Chang PW, Kuzniewicz MW, McCulloch CE, Newman TB. A Clinical Prediction Rule for Rebound Hyperbilirubinemia Following Inpatient Phototherapy. Pediatrics 2017;139:e20162896.

19. Barak M, Berger I, Dollberg S, Mimouni FB, Mandel D. When should phototherapy be stopped? A pilot study comparing two targets of serum bilirubin concentration. Acta Paediatr 2009;98:277-81.

20. Barrington KJ, Sankaran K; Canadian Paediatric Society Fetus and Newborn Committee. Guidelines for detection, management and prevention of hyperbilirubinemia in term and preterm newborn infants. Paediatr Child Health 2007;12(Suppl B):1B-12B. 